\title{
DESIGN AND IMPLEMENTATION OF A CO2 FLOOD UTILIZING ADVANCED RESERVOIR CHARACTERIZATION AND HORIZONTAL INJECTION WELLS IN A SHALLOW SHELF CARBONATE APPROACHING WATERFLOOD DEPLETION
}

Cooperative Agreement Number:

Contractor Name and Address:

Date of Report:

Award Date:

Anticipated Completion Date:

Government Award for 1995 Fiscal Year:

Project Director:

DOE Project Officer:

Reporting Period:
DE-FC22-94BC14991

Phillips Petroleum Company

4001 Penbrook

Odessa, Texas 79762

November 3, 1995

June 3, 1994

January 2, 2001

$\$ 138,881$

D. R. Wier

Jerry Casteel

July 1, 1995 - September 30, 1995

\section{DISCLAIMER}

This report was prepared as an account of work sponsored by an agency of the United States Government. Neither the United States Government nor any agency thereof, nor any of their employees, makes any warranty, express or implied, or assumes any legal liability or responsibility for the accuracy, completeness, or usefulness of any information, apparatus, product, or process disclosed, or represents that its use would not infringe privately owned rights. Reference herein to any specific commercial product, process, or service by trade name, trademark, manufacturer, or otherwise does not necessarily constitute or imply its endorsement, recommendation, or favoring by the United States Government or any agency thereof. The views and opinions of authors expressed herein do not necessarily state or reflect those of the United States Government or any agency thereof.

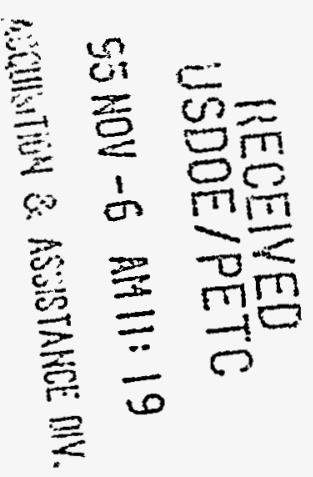




\section{OBJECTIVE}

The first objective is to utilize reservoir characterization and advanced technologies to optimize the design of a $\mathrm{CO}_{2}$ project for the South Cowden Unit (SCU) located in Ector County, Texas. The SCU is a mature, relatively small, shallow shelf carbonate unit nearing waterflood depletion. The second objective is to demonstrate the performance and economic viability of the project in the field. The work reported here is on the reservoir characterization and project design objective. This objective is scheduled to be completed in October of 1995 at which time work on the field demonstration phase is scheduled to begin.

\section{SUMMARY OF TECHNICAL PROGRESS}

\section{Injection Well Condition Database}

All injection well surveys were reviewed and tabulated for percentage injection into each stratigraphic layer and any losses above or below the defined layers (75 surveys among 24 injectors). In the project area, the injection into the chaotic interval correlated well with the reservoir simulation results.

\section{Geological-Petrophysical Interpretation of the Stratigraphic Framework}

For the 20 wells with core porosity data, conventional porosity-permeability regression equations were derived for the three rock groups: chaotic, grainstone, and low permeability. The semilog correlation model was used for permeability as a function of porosity:

$$
\log _{10}(k)=A_{0}+A_{1} * \text { PHI }
$$

where $k$ is permeability in millidarcies, $P H I$ is effective porosity in percent, and $A_{0}$ and $A_{1}$ are the correlation coefficients. The correlation coefficients for each cored well are listed in Table I, grouped by rock type. The field-wide correlations using all the core data available are also given in the table.

The field-wide correlation equations for the grainstone and low permeability rock groups will be used for the wells without core data. A single correlation equation will not successfully represent the permeability variation within the chaotic facies, as evidenced by field response during depletion and waterflood production performance. Given a general assumption that the chaotic facies dominates oil production performance in South Cowden Field, then production performance data could be used to indicate permeability. Other important assumptions in this approach are that the chaotic zone is the only zone completed; net thickness, pressure, and drainage areas are equivalent across the field, and that completion efficiency is comparable for all wells. If these assumptions hold, then Darcy's Law shows that effective permeability is a function of flow rate: 


$$
k=\frac{Q^{*}\left[\ln \left(\mathbf{r}_{e} / \mathbf{r}_{w}\right)+s\right]}{h^{*}\left(\mathbf{p}_{e}-\mathbf{p}_{w f}\right)}
$$

where $Q$ is total flow rate, $k$ is permeability, $h$ is net thickness, $p_{e}$ is pressure at the external bounday of the drainage area, $p_{w f}$ is the wellbore producing pressure, $r_{c}$ is the radius of the drainage area, $r_{w}$ is the wellbore radius, and $s$ is the skin effect.

Production plots for the cored wells were examined to determine a characteristic stable total liquid production rate for each well. Usually the maximum total liquid production rate was used, but wells with known water production from the lower grainstone were reviewed to estimate a characteristic flow rate from the chaotic interval only. Stable water injection rates were also reviewed, but did not show a correlation with core permeability. The correlation between geometric average core permeability and chacteristic flow rate is illustrated in Figure 1. The regression equation is

$$
\log _{10}\left(k_{\text {avg }}\right)=-2.6441+1.28598 * \log _{10}\left(Q_{\text {char }}\right)
$$

Given a characteristic fluid production rate for each well in the field, average permeability can be computed using the above equation. For water injection wells, average permeability will be estimated from offset production wells. Average porosity for the reservoir interval is computed from the interpreted well log curves. The average slope of permeability-porosity regression curves from individual cores for the chaotic facies is 0.12 . A regression formula is derived for each well in the field using the above slope and average porosity and permeability values thus:

$$
\log _{10}(k)=0.12 *\left(\mathrm{PHI}-\mathrm{PHI}_{\text {avg }}\right)+\log _{10}\left(\mathrm{k}_{\text {avg }}\right)
$$

Permeability curves will be computed for every well with a porosity curve in this fashion. The permeability curves will then be used to model a 3-dimensional distribution in the same manner as porosity.

\section{South Cowden $\mathrm{CO}_{2}$ Miscible WAG Trapped Gas Experiments}

Laboratory experiments were conducted and literature data were assessed to determine if significant water would be removed if dry versus wet $\mathrm{CO}_{2}$ were utilized during the latter part of the $\mathrm{CO}_{2}$ injection phase. For the amount of $\mathrm{CO}_{2}$ being injected, it was concluded that use of dry $\mathrm{CO}_{2}$ would not make a significant difference in the results.

\section{Laboratory Corefloods to Identify Potential Foaming Surfactants for $\mathrm{CO}_{2}$ Mobility Control}

The primary objective of this subtask was aimed at identifying specific foaming surfactants which may be needed for $\mathrm{CO}_{2}$ mobility control in the South Cowden project through a five part 
laboratory program. Following a $\mathrm{CO}_{2}$-foam test with 500 ppm Chaser ${ }^{\mathrm{TM}} \mathrm{CD}-1045$ in a South Cowden core at $70-100 \%$ foam quality (reported last June), two tests were performed with 1000 ppm Chaser ${ }^{\mathrm{TM}} \mathrm{CD}-1045$ at $50-100 \%$ foam quality. However, due to the dissolution of core material, the front end of the core collapsed at completion of the third experiment. The same experiments were repeated in a different core using $20-100 \%$ foam quality. However, the second core also collapsed at the face due to dissolution of core material and weakening of the core inlet. To avoid this problem, a short South Cowden field core designated as the "Pre-Foamer" core was placed ahead of the "test core". This modification improved the longevity of the test core and allowed completion of the performance evaluation of four surfactants at three concentrations with foams of $20-100 \%$ quality. In these tests the average resistance factor (RF) for the four sections of the core was measured as a function of foam quality.

The foam produced with 500 ppm Rhodapex $\mathrm{CD}-128$ and $\mathrm{CO}_{2}$ had a maximum $\mathrm{RF}$ around $50 \%$ foam quality. This maximum is shifted to about $70 \%$ foam quality for solutions of $1000 \mathrm{ppm}$ and 2000 ppm Rhodapex CD-128. A similar behavior was observed for Foamer NES-25, Chaser TM CD-1050 and Chaser ${ }^{\mathrm{TM}}$ CD-1045. Results indicate that Rhodapex CD-128 and Chaser ${ }^{\mathrm{TM}} \mathrm{CD}$ 1050 produced the best foams followed by Chaser ${ }^{\mathrm{TM}}$ CD-1045 and Foamer NES-25.

The effect of foam quality on resistance factor was examined for the four sections of the core when mixtures of 500 ppm Rhodapex CD-128 and $\mathrm{CO}_{2}$ were co-injected into the core. The permeability for sections $1,2,3$ and 4 of this core were $486 \mathrm{md}, 216 \mathrm{md}, 46 \mathrm{md}$ and $41 \mathrm{md}$, respectively. The data indicate that resistance factor increases with permeability of the section. A similar behavior was observed for all four surfactants tested in this core. This effect which might occur at a given rock permeability is desirable and would improve the efficiency of foam to block the higher permeability zones to a larger extent. This effect was first observed by J. P. Heller and his group at New Mexico Petroleum Recovery Research Center.

\section{Reservoir Simulation Studies for Project Design and Performance Forecasting (90\% Complete)}

Full-field simulations were completed to evaluate various combinations of horizontal and vertical $\mathrm{CO}_{2}$ WAG injection wells. The most effective well configuration for South Cowden utilizes horizontal $\mathrm{CO}_{2}$ WAG injectors in downdip locations, oriented approximately parallel to structural strike, in combination with vertical WAG injection wells in updip locations. Vertical permeability restrictions in the lower portion of the main reservoir interval limit the vertical distribution of injected $\mathrm{CO}_{2}$ into these lower intervals if only horizontal injection wells are used. In the downdip locations, much of the reservoir pore volume in the lower intervals lies below the original oil-water contact.

Preliminary sensitivity studies were conducted to investigate the effects of the $\mathrm{CO}_{2}$ WAG injection strategy on project performance. Incremental oil recovery vs. WAG ratio results from these simulations showed that WAG operations produced significant increases in oil recovery efficiency compared with continuous $\mathrm{CO}_{2}$ injection. Maximum oil recovery was obtained at a 
WAG ratio of approximately 2:1, however the time required to inject a given total volume of $\mathrm{CO}_{2}$ was significantly longer at this higher WAG ratio. A hybrid WAG injection scheme is premised in the preliminary project design. This provides an economic compromise of increased oil recovery efficiency vs. continuous $\mathrm{CO}_{2}$ injection, while accelerating incremental oil response and reducing overall project life vs. a straight 2:1 WAG process.

Performance forecasts were generated for a base case project development plan. Incremental oil recovery forecasted for the base case project is $10.4 \%$ OOIP. The full-field simulator was also used to assess the effect of uncertainties in key input and operating parameters on production profiles and recoverable reserves for use in project risk analysis. Major elements of uncertainty having the largest impact on performance forecasts were identified by the project team. These grouped into three major categories - reservoir characterization/heterogeneity/sweep efficiency; $\mathrm{CO}_{2}$ process efficiency/target oil volume; and well completion efficiency/injectivity (with the greatest focus on horizontal well completion effectiveness).

\section{Design Upgrades and Additions to Production and Injection Facilities}

A team of engineers and construction personnel were assembled to document the premises to be used in field implementation of the project development plan. This team designed the equipment and facility upgrades and additions required for the project, laid out the schedule for implementation and forecasted the capital and operating costs. The schedule and costs were subsequently used in the economic and risk analysis assessment of the project.

\section{Generation of an Authority for Expenditure (AFE)}

An economic evaluation of the project was made based on the development schedule, capital investment, operating cost and production forecast for the project development plan. An associated full risk analysis was also performed on four variables considered the most critical to the South Cowden $\mathrm{CO}_{2}$ project: oil price, reserves/recovery efficiency, capital investment and operating expenses.

Based on favorable results from the economic and risk analysis evaluation, an AFE for field implementation of the project was submitted to the unit working interest owners (WIO) in September. The AFE was subsequently approved by the WIO's and field implementation of the project is scheduled to begin in late October of 1995.

\section{Technology Transfer}

An abstract for a paper, to be entitled "Determination of Relative Permeability and Trapped Gas Saturation for Predictions of WAG Performance in the South Cowden $\mathrm{CO}_{2}$ Flood", was submitted (by D. C. Wegener and K. J. Harpole) for evaluation by the program committee of the SPE/DOE Tenth Symposium on Improved Oil Recovery to be held in Tulsa in April of 1996. 
FIGURE 1

\section{Permeability v. Qchar}

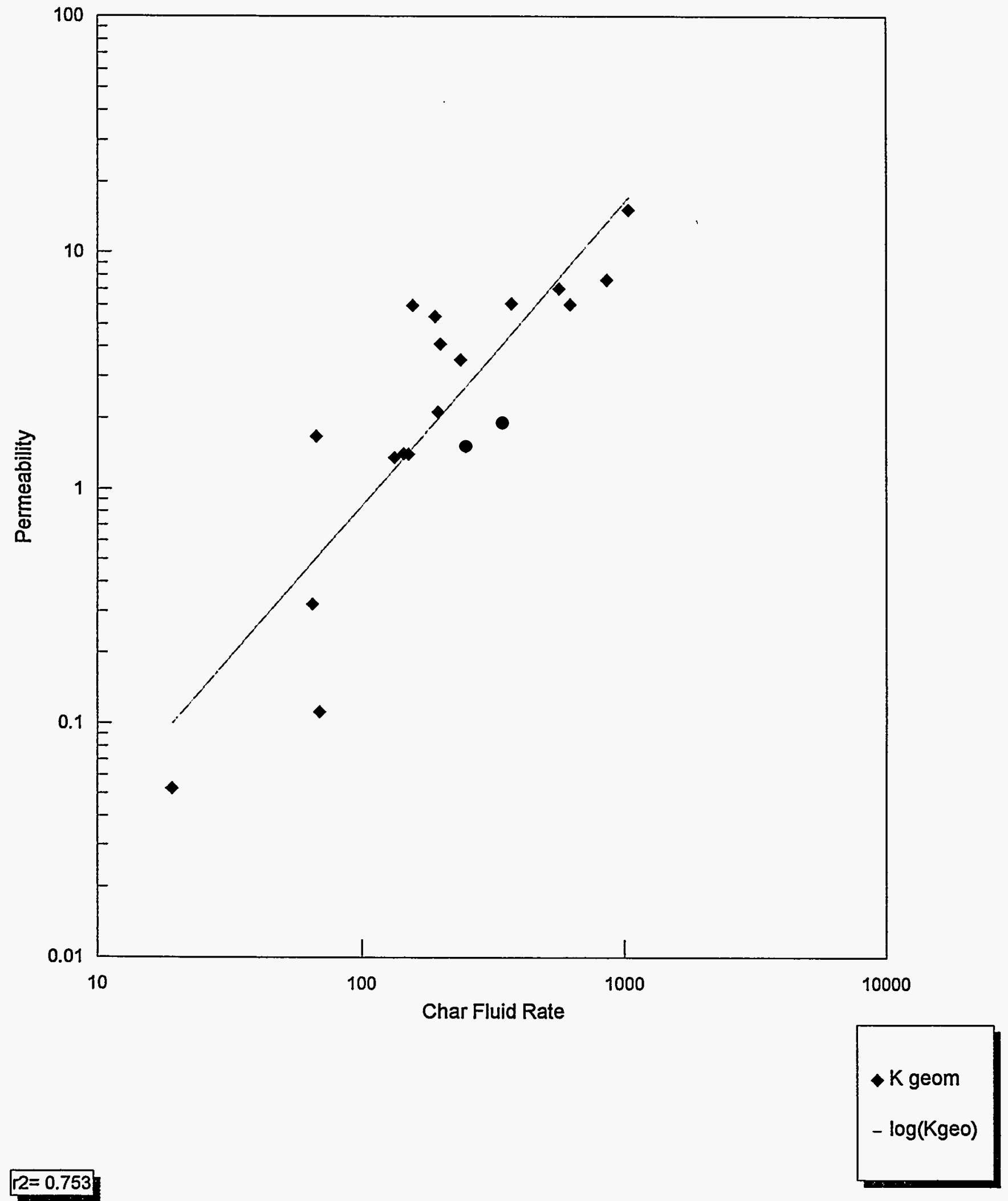




\section{TABLE I}

Permeability - Porosity Regression Equations

$$
\log 10(k)=A 0+A 1 * P H I
$$

\begin{tabular}{|c|c|c|c|c|c|c|c|c|c|}
\hline \multirow[b]{2}{*}{ Well } & \multicolumn{3}{|c|}{ Chaotic } & \multicolumn{3}{|c|}{ Grainstone } & \multicolumn{3}{|c|}{ Low Permeability } \\
\hline & AO & A1 & $\underline{\mathbf{r}}$ & $\mathrm{AO}$ & A1 & $\underline{r 2}$ & AO & A1 & $\underline{2}$ \\
\hline Field Wide & -1.1706 & 0.136 & 0.393 & -1.5493 & 0.1766 & 0.41 & -1.7115 & 0.1729 & 0.438 \\
\hline Scu 2-01 & & & & -1.8772 & 0.1463 & 0.516 & & & \\
\hline $\begin{array}{l}\text { SCU 2-14W } \\
\text { SCU 4-03W } \\
\text { SCU 6-18 }\end{array}$ & -1.142 & 0.0938 & 0.245 & -1.3941 & 0.1302 & 0.482 & $\begin{array}{l}-1.2638 \\
-2.3513 \\
-1.1828\end{array}$ & $\begin{array}{r}0.0884 \\
0.2593 \\
0.085\end{array}$ & $\begin{array}{l}0.355 \\
0.695 \\
0.104\end{array}$ \\
\hline SCU 6-18 & -0.6315 & 0.0971 & 0.205 & & & & & & \\
\hline SCU 6-21 & -0.04954 & 0.1121 & 0.237 & & & & & & \\
\hline SCU 6-23 & -0.8857 & 0.126 & 0.394 & & & & -2.381 & 0.265 & $\begin{array}{l}0.522 \\
0.294\end{array}$ \\
\hline $\begin{array}{l}\text { SCU 7-06 } \\
\text { SCU 7-09 }\end{array}$ & $\begin{array}{l}-0.5122 \\
-0.8863\end{array}$ & $\begin{array}{l}0.0877 \\
0.1068\end{array}$ & $\begin{array}{l}0.154 \\
0.273\end{array}$ & & & & -1.1761 & 0.0841 & 0.294 \\
\hline SCU 7-10 & -1.1954 & 0.1097 & 0.525 & -0.5618 & 0.1337 & 0.223 & -1.7992 & 0.1282 & 0.43 \\
\hline SCU 8-03 & -1.6361 & 0.1408 & 0.477 & & & & & & \\
\hline SCU 8-11W & -0.769 & 0.0918 & 0.234 & & & & -1.4903 & 0.1017 & 0.148 \\
\hline SCU 8-19 & -1.0272 & 0.1216 & 0.401 & -1.2531 & 0.2142 & 0.366 & -1.816 & 0.1378 & 0.243 \\
\hline Emmons 135 & -0.7197 & 0.139 & 0.322 & & & & -1.0026 & 0.1366 & 0.474 \\
\hline Emmons 146 & 0.1814 & 0.072 & 0.159 & & & & -0.6501 & 0.1913 & 0.558 \\
\hline Emmons 142 & -0.1261 & 0.081 & 0.265 & & & & -1.0075 & 0.2589 & 0.453 \\
\hline Emmons 146 & -1.0792 & 0.1252 & 0.613 & & & & & & \\
\hline Emmons 210 & -0.8545 & 0.1386 & 0.398 & -1.8603 & 0.1856 & 0.575 & -1.1902 & 0.0988 & 0.324 \\
\hline Emmons 213 & -1.053 & 0.1182 & 0.335 & & & & & & \\
\hline Emmons 216W & -0.8907 & 0.1121 & 0.455 & -1.7058 & 0.2163 & 0.721 & -1.4778 & 0.1469 & $\begin{array}{l}0.614 \\
0.288\end{array}$ \\
\hline Moss 6-9W & & & & & & & -1.2228 & 0.1022 & $\begin{array}{l}0.288 \\
0.086\end{array}$ \\
\hline Moss 13-6 & -1.9601 & 0.1505 & 0.242 & -2.0903 & 0.1502 & 0.689 & -1.911 & 0.1655 & 0.086 \\
\hline Moss $16-14$ & -1.8323 & 0.1042 & 0.138 & -2.0992 & 0.1756 & 0.66 & -1.8333 & 0.1929 & 0.3 \\
\hline
\end{tabular}

